UCRL-JC-123850

PREPRINT

CONF- $960706--14$

\title{
Analysis of "Soft" Recovered Shaped Charge Jet Particles
}

D. H. Lassila

W. P. Walters

D. J. Nikkel, Jr.

R. P. Kershaw

This paper was prepared for submittal to the

Symposium Structures Under Extreme Loading Conditions at the

1996 American Society of Mechanical Engineers Pressure Vessels and Piping Conference

Montreal, Canada

July 21-26, 1996

April 1996

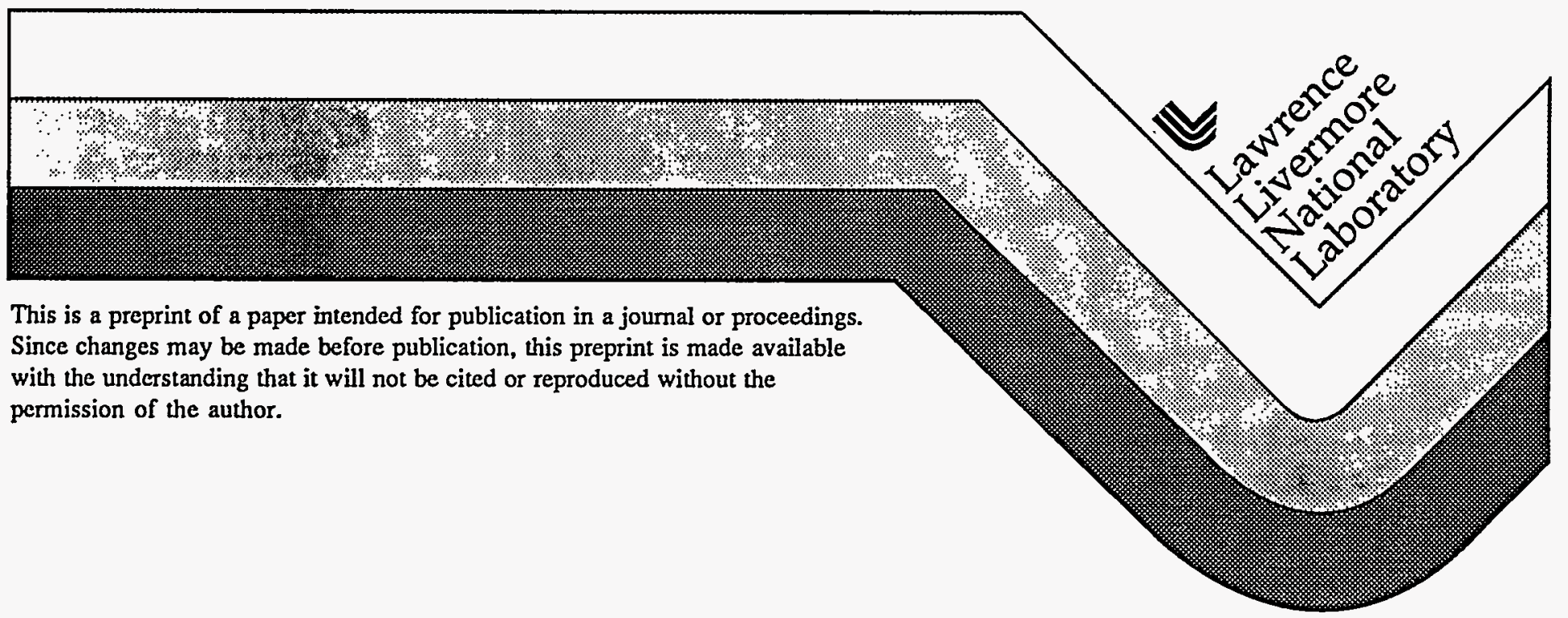

DISTRBBUTION OF THIS DOCUMENT IS UNLMMTED WT 


\section{DISCLAIMER}

This document was prepared as an account of work sponsored by an agency of the United States Government. Neither the United States Government nor the University of California nor any of their employees, makes any warranty, express or implied, or assumes anylegalliability or responsibility for the accuracy, completeness, or usefulness of any information, apparatus, product, or process disclosed, or represents that its use would not infringe privately owned rights. Reference herein to any specific commercial products, process, or service by trade name, trademark, manufacturer, or otherwise, does not necessarily constitute orimply jts endorsement, recommendation, or favoring by the United States Government or the University of California. The views and opinions of authors expressed herein do not necessarily state or reflect those of the United States Government or the University of California, and shall not be used for advertising or product endorsement purposes. 


\title{
ANALYSIS OF "SOFT" RECOVERED SHAPED CHARGE JET PARTICLES
}

\author{
David H. Lassila1, William P. Walters ${ }^{2}$, Daniel J. Nikkel, Jr. ${ }^{1}$, \\ and Robert P. Kershaw ${ }^{1}$
}

1. University of California, Lawrence Livermore National Laboratory, Livermore, California 94550

2. U.S. Army Research Laboratory, Aberdeen Proving Ground, Maryland 21005

\begin{abstract}
A shaped charge with an $81 \mathrm{~mm}$ diameter, $42^{\circ}$ apex angle oxygen-free high-conductivity (OFHC) copper conical liner was fired into a "soft" recovery bunker to allow metallurgical examination of recovered jet particles and the slug. The initial weight of the copper liner was $245 \mathrm{~g}$, of which $184 \mathrm{~g}$ was recovered. The number of jet particles recovered was 37 (approximately $63 \%$ of the particles formed by the charge.) Extensive metallurgical analyses were performed on the recovered slug and jet particles. The microstructural features associated with voids, e.g., dendritic grain growth, clearly indicate that the regions in the vicinity of the centerline of the slug and jet particles were melted. In this work we present calculations of jet temperature as a function of constitutive behavior. In order to predict melt in the center region of the jet we find it necessary to scale flow stress with a pressure dependent shear modulus.
\end{abstract}

\section{INTRODUCTION}

The fundamental metallurgical and physical parameters that affect the elongation of shaped charge jets (after jet formation) are, to a large extent, unknown. Some metallurgical effects have been demonstrated; for example, some impurity contents can lead to very brittle and particulated breakup (Lichtenberger, 1989), (Hirsch, 1990), (Caligiuri and Smith, 1984), (Lassila, 1992), and (Angerson et. al., 1995). Several studies have focused on breakup analyses from a mechanics viewpoint (addressing the ductile necking process from a continuum point of view) and have suggested that breakup is affected by the jet's constitutive behavior and/or radial inertia (Chou and Carleone, 1977), (Hirsch, 1985), (Walters and Zukas, 1989), (Walters and Summers, 1995), and (Walters and Summers, 1993). Also, initial perturbations in the jet caused by fluctuations in the jet formation process are also believed to affect jet ductility (Chan et. al., 1995). In a recent study, it has also been shown that changes in the concentration of sulfur at grain boundaries can affect the ductile necking process (Chan et. al., 1995). Jet recovery attempts and metallurgical analyses (Zernow, 1988), (Lichtenberger and Zernow, 1993), (Zernow et. al., 1993), (Gurevitch et. al., 1993), (Mostert et. al., 1995) are useful in the progress being made in understanding the phenomena associated with jet melting (Zernow, 1990) and associated stretching processes (Hirsch, 1993).

In this work we present metallurgical examinations of "soft recovered" copper jet particles and slug that indicate a central region of approximately $10 \%$ of the jet's diameter was molten. We also present calculations of jet temperature which are in good agreement with both the external jet region presented in this work.

\section{“SOFT" RECOVERY EXPERIMENT}

A shaped charge $\left(81 \mathrm{~mm}, 42^{\circ}\right.$, OFHC copper cone) was fired into a "soft" recovery bunker to allow metallurgical examination of recovered jet particles and the slug. The soft recovery has a $1.2 \mathrm{~m}$ by $1.2 \mathrm{~m}$ cross-section and consists of $1.6 \mathrm{~m}$ of air, $1.8 \mathrm{~m}$ of shaving cream, $9 \mathrm{~m}$ of foam with graded density, and $3.6 \mathrm{~m}$ of water, as shown in Fig. 1. The styrofoam was surrounded by plywood on two sides and contained a plywood floor. The plywood was used to provide positive evidence of any particle which may exit the recovery medium. The water was used as a backstop, the intent being to capture all particles in the styrofoam. In the actual test, one jet particle was recovered in the water. The initial weight of the copper liner was $245 \mathrm{~g}$, of which $184 \mathrm{~g}$ was recovered. The typical number of jet particles produced by the shaped charge that was fired is approximately 59 , as determined by flash radiographs. The number of jet particles recovered was 37 , or approximately $63 \%$ of the particles. 


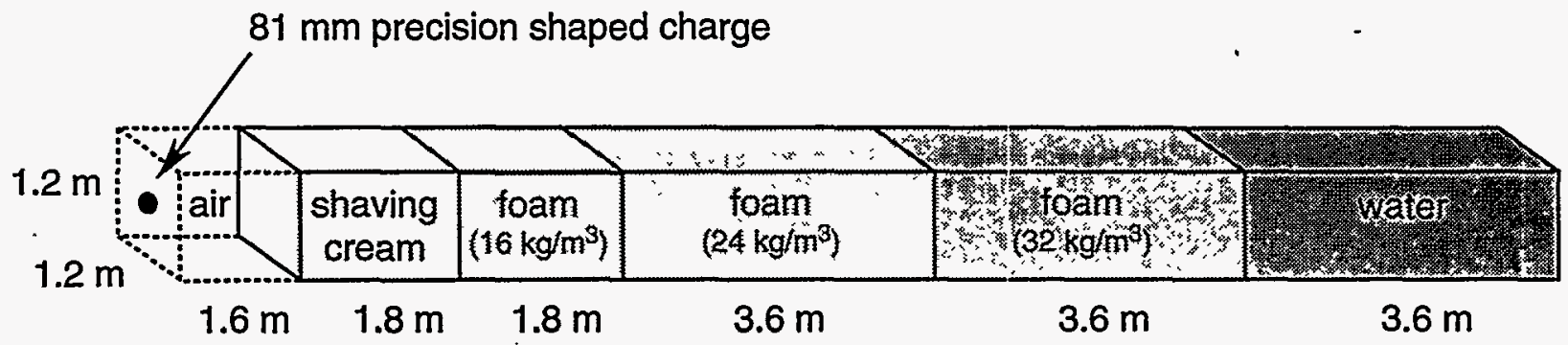

Figure 1. Shaped charge jet "soft" recovery test setup. The shaving cream was contained in a box with plywood sides and plastic faces.

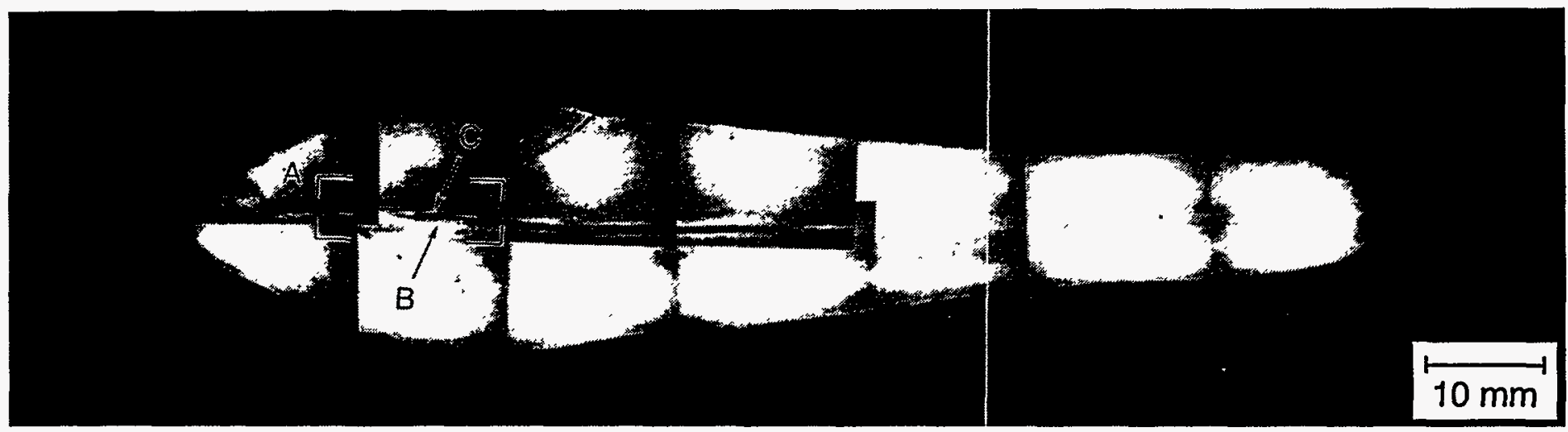

Figure 2. Low magnification photograph of the "soft" recovered slug. A central void region is located where convergence occurred during jet formation (A). High magnification photographs of the features at points $B$ and $C$ are shown in Figures 3 and 4 , respectively.

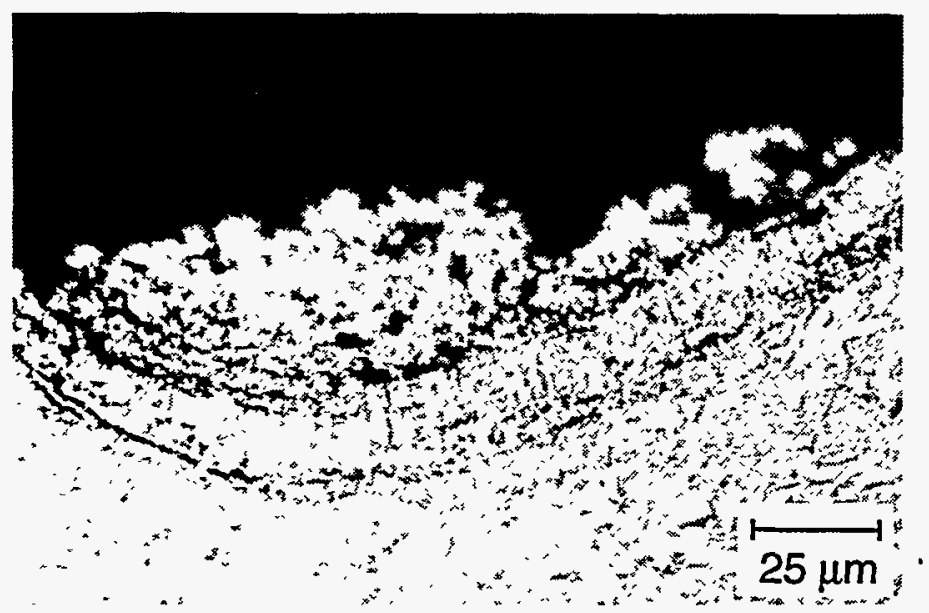

Figure 3. Micrograph of material adjacent to the void region in the slug showing dendritic grain structure (point $B$ in Fig. 2). This indicates that this area in the slug was melted and cooling occurred relatively slowly, producing a columnar grain structure.

\section{METALLOGRAPHIC EXAMINATIONS}

Extensive metallurgical analyses (optical light microscopy and scanning electron microscopy [SEM]) were performed on the recovered slug and jet particles. The preparation of metallographic samples was as follows: the recovered objects were sectioned longitudinally so that the observed surface corresponded roughly to the center plane; the samples were then polished and subsequently etched with ammonium persulfate.

\section{slug}

The microstructural features associated with voids in the vicinity of the convergence zone in the slug, as shown in Fig. 2, clearly indicate that this region was molten at some point. Dendritic grain structure adjacent to the void region in the slug (Fig. 3) indicates that this area in the slug was melted and cooling occurred relatively slowly, producing a columnar grain structure. Also, spherical particles are observed in the void (Fig. 4), which is consistent with solidification of molten material. Some areas of the voids in the slug were covered with a slag (Fig. 5), which in general, had a smooth modeled appearance. This by itself is a clear indication that this region was molten. The slag also had many 


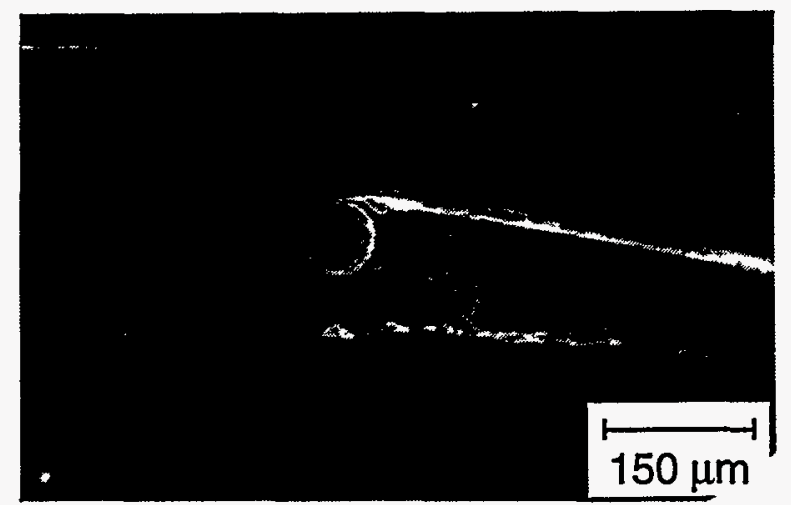

Figure 4. Spherical particles (point $C$ in Fig. 2) in the void also indicate that this region was melted.

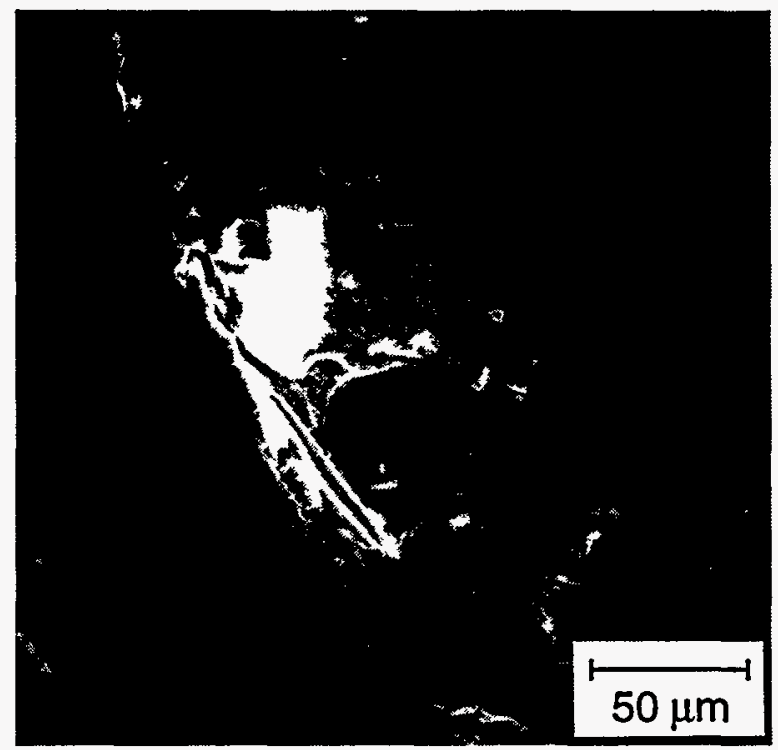

Figure 5. A portion of the surface of the void region in the slug is covered with a slag that has numerous cracks. small cracks, which suggests the slug was brittle and possibly an intermetallic compound. Void regions were also observed in earlier studies (Lichtenberger and Zernow, 1993) and (Zernow et. al., 1993).

\section{Jet Particles}

Metallurgical analyses were performed on most of the larger recovered jet particles. An optical light micrograph of a recovered particle showing void regions running approximately down the center is shown in Fig. 6. An SEM photograph of an area of one of the central voids in a recovered jet particle is shown in Fig. 7. This micrograph reveals the porous nature of the void and also surface features which are modeled and spherical in nature. These types of voids were typical in many of the recovered particles and suggest that a region approximately equal to $10 \%$ of the jet diameter was molten. The series of elliptical voids observed in the neck region may be associated with the tensile failure (necking) that occurred during jet elongation.

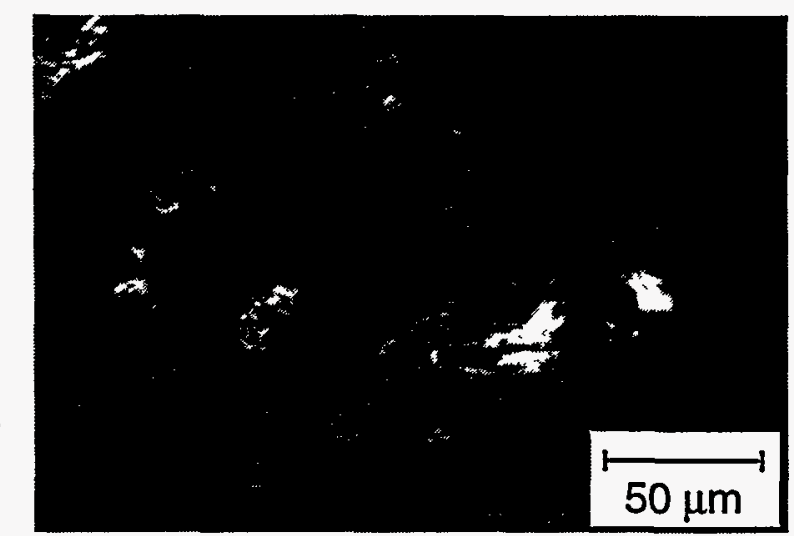

Figure 7. Scanning electron microscope photograph of an area of one of the central voids in a recovered jet particle revealing the porous nature of the void and also surface features that are spherical in nature.

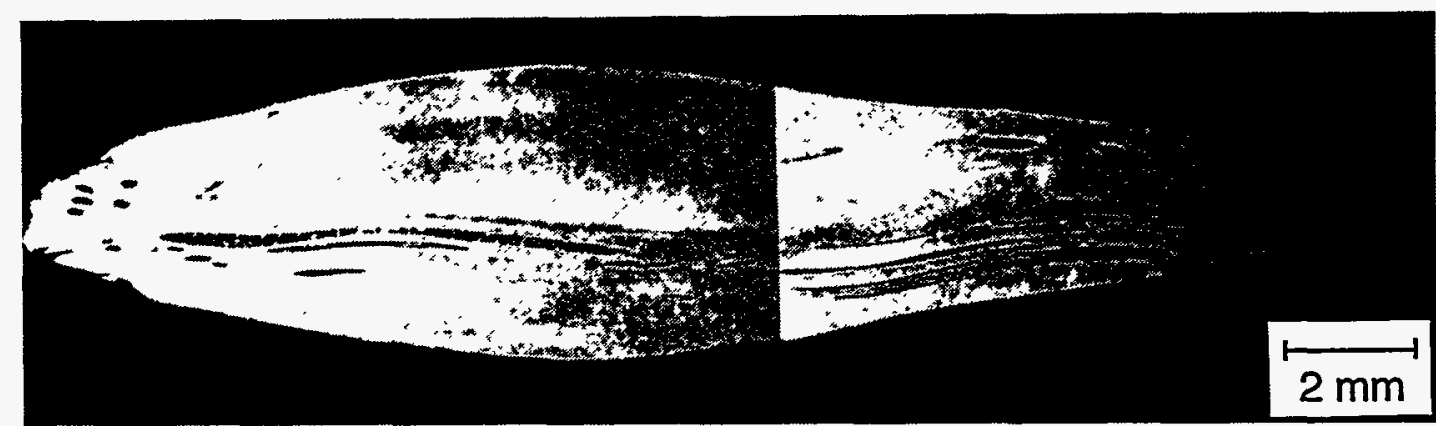

Figure 6. Micrograph of a recovered particle showing void regions running approximately down the center. A series of elliptical voids that are observed in the neck region may be associated with the tensile failure. 


\section{CALCULATION OF JET TEMPERATURE}

- Nikkel and Lassila (1993) calculated the temperature at one location in a shaped charge jet. The methodology employed involved the use of strain and pressure histories determined by an explicit Eulerian computer code simulation of a shaped charge (which was relatively insensitive to the material strength model.) A computer program called "JET" was then used to solve the equations that specified the problem, e.g., the equation of state, a strength model, and a temperature dependent specific heat. It was determined that the pressure dependence of the shear modulus had a dominant effect on strength because of the very high pressures and shear deformations which occur in the convergence zone.

In this work we use the same methodology described previously to predict the temperature profile through the thickness of a jet at approximately the midpoint along the length. A computer simulation of a BRL precision shaped charge was performed using CALE (Tipton, 1994), which is an arbitrary Lagrange-Eulerian computer code. A total of nine tracer particles were used to determine strain and pressure histories. The tracer particle locations are shown in Fig. 8. Representative tracer particle strain and pressure histories are shown in Fig. 9.
The Mechanical Threshold Stress material model as given in Gourdin and Lassila (1991) was used in the calculation with and without a pressure dependent shear modulus. The pressure dependence of the shear modulus used is that formulated by Steinberg and Guinan (1980). The stress-strain response determined for tracer 5, shown in Fig. 10, indicates substantially higher flow stresses when a pressure dependent shear modulus is used in the calculation.

The temperatures calculated, using a pressure dependent modulus, for all of the tracers are shown in Fig. 11. The temperature profile for the jet is shown in Fig. 12 and with some interpolation indicates that approximately $13 \%$ of the jet is melted, which is in good agreement with the indication of melt in the recovered jet particles. Also, the predicted temperature of the exterior of the jet, $500^{\circ} \mathrm{C}$, is in good agreement with the jet temperature measurements of Von Holle and Trimble (1976).
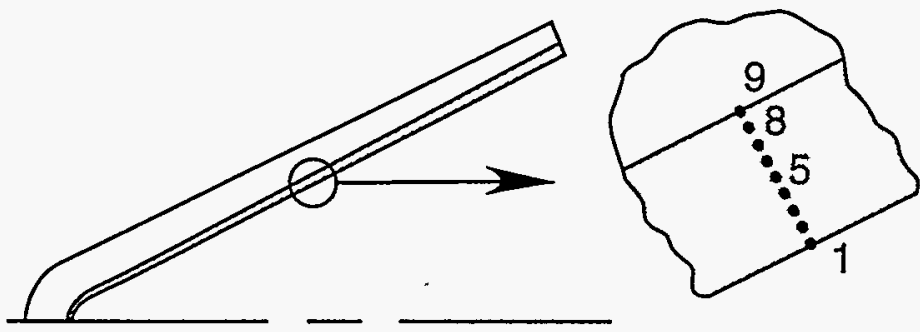

Portion of liner which forms the jet

Tracer \#1 $\rightarrow \quad$ surface of jet Tracer \#5 $\rightarrow$ mid radius of jet Tracer \#9 $\rightarrow \quad$ center of jet

Figure 8. Cross section of a liner showing the tracer particle locations.

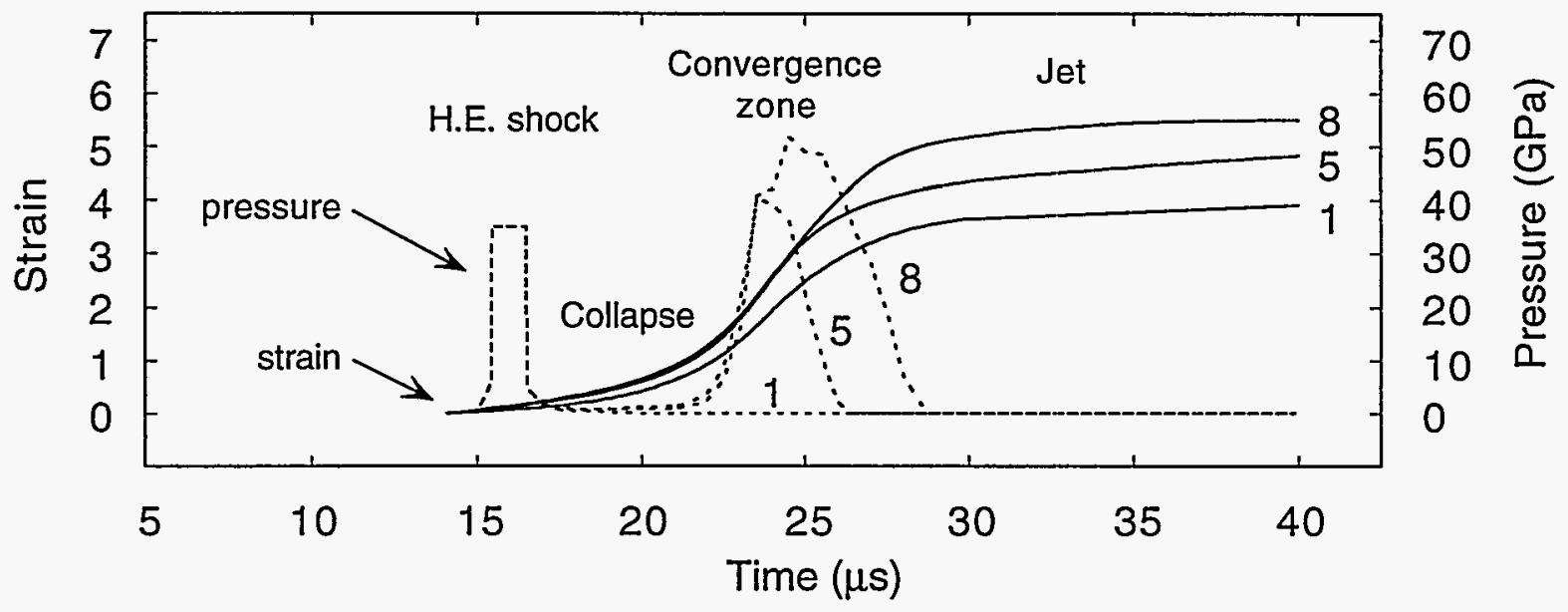

Figure 9. Strain and pressure histories from tracer particle number 5 . 


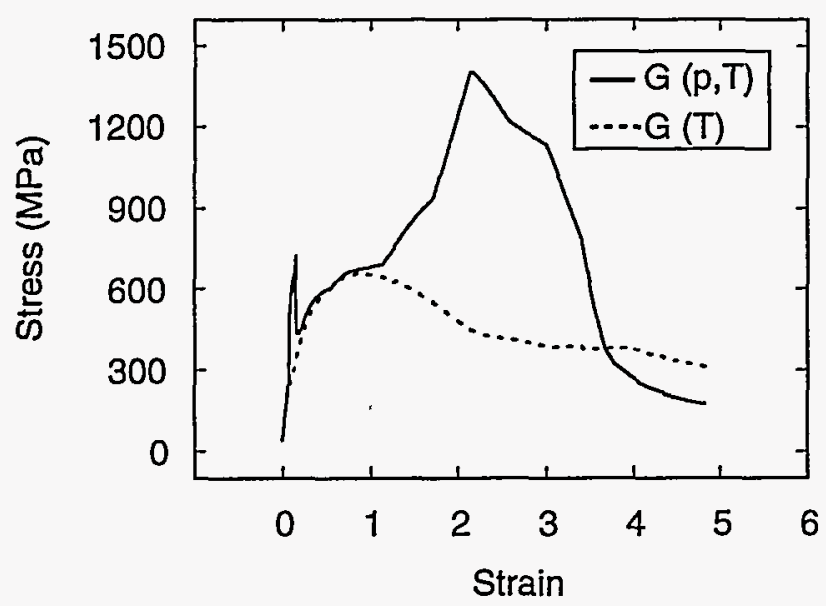

Figure 10. Calculated stress-strain response with and without a pressure dependent shear modulus.

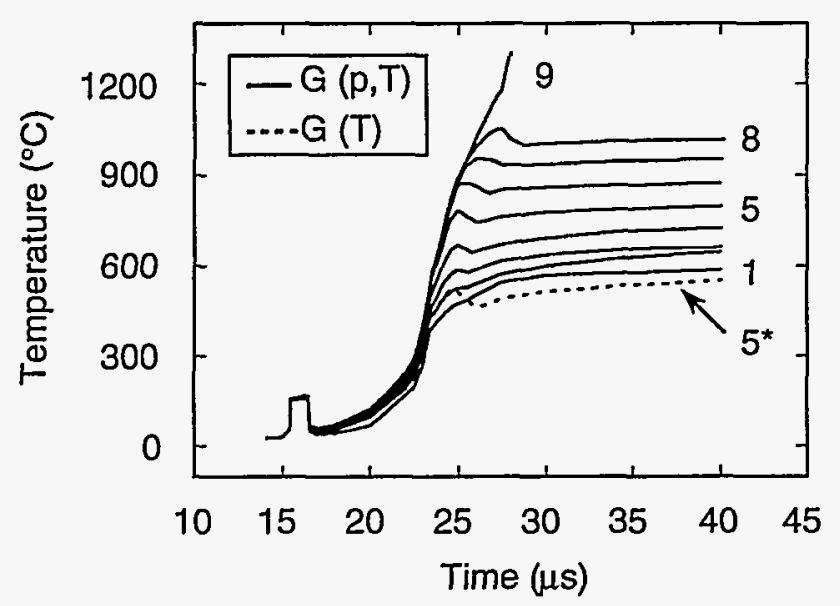

Figure 11. The calculated temperature histories of the nine tracer particles shown in Figure 8.

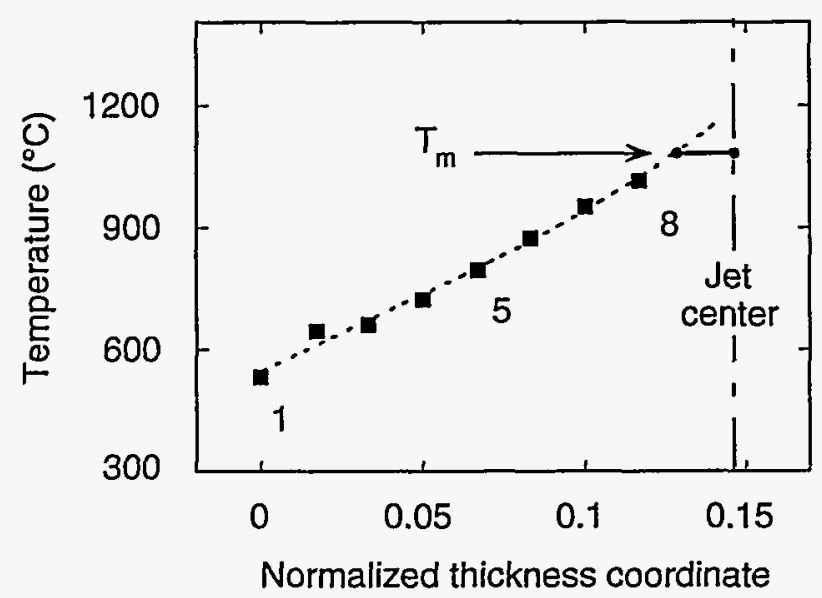

Figure 12. Variation of the final temperature from the outer surface to the center line of the jet.

\section{SUMMARY}

A shaped charge with an $81 \mathrm{~mm}$ diameter, $42^{\circ}$ apex angle OFHC copper conical liner was fired into a "soft" recovery bunker to allow metallurgical examination of recovered jet particles and the slug. The metallurgical analyses (optical light microscopy, SEM) performed on the recovered slug and jet particles indicate that the regions in the vicinity of the centerline of the slug and jet particles were melted. Our calculations of jet temperature as a function of constitutive behavior are in reasonable agreement with these observations if a pressure dependent shear modulus is incorporated in the constitutive model for the liner material.

\section{ACKNOWLEDGMENTS}

The CALE computer code tracer particle data were provided by Dr. S. C. Simonson. The SEM microscopy was performed by $\mathrm{Mr}$. J. M. Yoshiyama. The support of the Joint DOD/DOE Munitions Technology Program is gratefully acknowledged. This work was performed under the auspices of the U.S. Department of Energy by the Lawrence Livermore Laboratory under contract No. W-7405ENG-48.

\section{REFERENCES}

Anderson, G., Janzon, B., Karlsson, S., and Watterstam, A., 1995, "A Study of Grain Size Effects on the Performance of Cold Pressed Shaped Charge Liners," 15th International Symposium on Ballistics, Jerusalem, Israel, Vol. 2.

Caligiuri , R. and Smith, J., 1984, "Influence of Microstructure on the Performance of Explosively Driven Liners," Proceedings of the 8th International Symposium on Ballistics , Orlando, FL.

Chan, D., Lassila, D., and Baker, E., 1995, Private Communication, Lawrence Livermore National Laboratory, Livermore, CA.

Chou, P., and Carleone, J., 1977, "The Stability of Shaped Charge Jets," Journal of Applied Physics, Vol. 48, no. 10, pp. 4187-4195.

Gourdin, W., and Lassila, D., 1991, "Flow Stress of OFE Copper at Strain Rates from $10^{-3}$ to $10^{4} \mathrm{~s}^{-1}$ : Grain Size Effects and Comparison to the Mechanical Threshold Stress Model," Acta Metall. Mater., Vol. 39, No. 10, pp. 2337-2348.

Gurevitch, A., Murr, L., Shih, H., Niou, C., Advani, A., Manuel, D., and Zernow, L., 1993, "Characterization and Comparison of Microstructures in the Shaped-Charge Regime: Copper and Tantalum," Materials Characterization, Elsevier Science Publishing Co. Inc., New York, NY, Vol. 30, pp. 201216.

Hirsch, E., 1985, “A Relation between the Liner Kinetic Energy and the Distance reached by the Shaped Charge Jet at the Moment of Particulation," Propellants, Explosives, Pyrotechnics, Vol. 10, pp. 74-76.

Hirsch, E., 1990, "The Effect of the Liner Metallurgical State on the Shaped Charge Jet Break-Up Time," Propellants, Explosives, Pyrotechnics, Vol. 15, pp. 166-176. 
Hirsch, E., 1993, "How does the Shaped Charge Jet Become Hollow?," Proceedings of the 14th International Symposium on Ballistics, Quebec, Canada, pp. 29-38.

Lassila, D., 1992, "Correlations Between Shaped Charge Jet Breakup and Grain Boundary Impurity Concentrations," Proceedings of the 13th International Symposium on Ballistics, Stockholm, Sweden.

Lichtenberger, A., 1989, "Some Criteria for the Choice of Shaped Charge Copper Liners," Proceedings of the 11th International Ballistics Symposium, Brussels, Belgium, Vol 2, pp. 103-109.

Lichtenberger, A., and Zernow, L., 1993, "Increase of Jet Ductility With Cold Pressed Lines and Recovery of Jet Fragments," 14th International Symposium on Ballistics, Quebec, Canada, Vol. 2.

Mostert, F., Smit, G., Werneyer, K., 1995, "Analysis of Jet Properties of Different Liner Materials Manufactured Under Various Conditions," 15th International Symposium on Ballistics, Jerusalem, Israel, Vol. 2.

NikkeI, D. Jr., and Lassila, D., 1993, "The Effect of the Constitutive Response on the Predicted Temperatures in Copper Jets," High Pressure Science and Technology-1993, American Institute of Physics Conference Proceedings 309, Part 2, pp. 1857-1860.

Schmidt, C., et. al., 1990, "Investigation of the High-StrainRate behavior of Materials for Anti-Armor Systems," SRI International Final Report for University of California LLNL.

Steinberg, D., Cochran, S., and Guinan, M., 1980, “A Constitutive Model for Metals Applicable at High-Strain Rate," $J$. Appl. Phys., Vol. 51, No.3, pp. 1498-1504.

Tipton, R., 1994, CALE Users Manual, Lawrence Livermore National Laboratory, Livermore, CA.

Von Holle, W., and Trimble, J., 1976, "Shaped Charge Temperature Measurement," Proceedings Sixth Symposium (International) on Detonation, NSWC, ACR-221 ONR.

Walters, W., and R. Summers, 1993, "A Review of Jet Breakup Time Models," Propellants, Explosives, Pyrotechnics, Vol. 18, pp. 241-246.

Walters, W., and Summers, R., 1995, "An Analytical Model for the Particulation of a Jet From a Shaped Charge Liner," Propellants, Explosives, Pyrotechnics, Vol. 20, pp. 58-63.

Walters, W., and Zukas, J., 1989, Fundamentals of Shaped Charges, Wiley Interscience, NY. p118.

Zernow, L., 1988, Int. Conf. on Ballistics, Nanjing, China.

Zernow, L., 1990, "Does Momentary Core Melting Occur in Copper Shaped Charged Jets?", Proc. of the 12th International Ballistics Symposium, San Antonio, TX, Vol 2, pp. 410-428.

Zernow, L., Herrmann, R., and Sedgwick, R., 1993, "Does the Dynamic Generation of Porosity in the Necking Jet Affect the Jet Particulation Process?," 14th International Symposium on Ballistics, Quebec, Canada, Vol. 2. 
Technical Information Department . Lawrence Livermore National Laboratory University of California - Livermore, California 94551

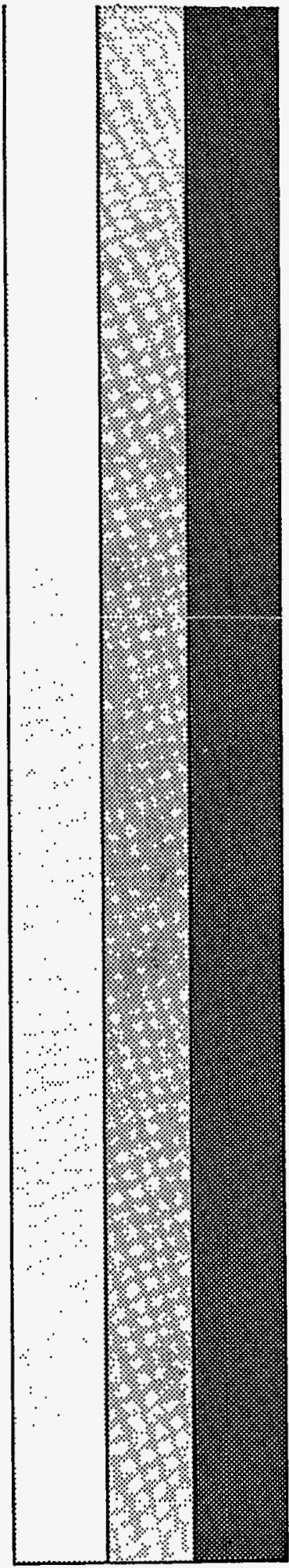

